Magdalena Malinowska

University of Szczecin

e-mail: magdalena.malinowska1@usz.edu.pl

\title{
THE APPLICATION OF FUZZY SETS TO DETERMINE THE CRITERIA OF THE SUSTAINABLE WAREHOUSING ASSESSMENT MODEL
}

\begin{abstract}
Background: The chapter presents an approach to elaborate the sustainable warehousing assessment model and applying the fuzzy set theory to determine the criteria for its purpose. This proposal goes beyond the already applied approach which aims on application the existing building certification standards i.eg. BREEAM or LEED and extends the range of the criteria towards the specify of warehouse and warehouse processes. Such approach is complied with context of sustainable warehousing in which the warehouse is a unit equipped by appropriate technological and organizational solutions allowing to operate maintaining the high standards of work, reduce the negative impact on the environment and achieve the lover cost of its functioning.
\end{abstract}

Methods: The COMET method is proposed to elaborate the sustainable warehousing assessment model. The COMET method is a multi-criteria decision-making method and allows to eliminate the phenomenon of rank reversal. According to the COMET method the set of criteria reflecting the range of considered problem with the scale of their measurement is determined. Moreover a set of linguistic numbers for each of the criteria was established and used to express the membership of each element of original scale to number expressed in natural language.

Results: The main result of the article is the application of COMET method for the purpose of sustainable warehousing assessment model elaboration and the definition of the set of criteria expressing by a set of fuzzy numbers to develop a model which allows to inferencing about the level of sustainable warehousing.

Conclusions: The article presents the original approach to apply the COMET method and utilize the fuzzy set to describe the criteria for the purpose of sustainable warehousing assessment model elaboration. Such approach allows to prepare the dedicated measure of the level of sustainable warehousing. 
Keywords: sustainable warehousing assessment model, sustainable warehousing, sustainability, COMET method

\section{INTRODUCTION}

Although the term of sustainability was firstly disseminated 300 years ago by Hans Carl von Carlowitz, as a part of his forest reconstruction policy and adopted again in the 1980s, the various challenges facing the global community in the $21^{\text {st }}$ century caused the necessity to look for new ways engaging to the idea of sustainability [El-Berishy et al. 2013]. This demand is nowadays widely spread among all business areas, including logistics. The logistic enterprises try to achieve balance between economic, environmental and social aspects of their functioning to deliver an integrated approach in various fields: transportation, warehousing, material handling, packaging, supply chain management, ect. Following towards sustainability requires, however, from one side the implementation of the organizational changes and from the other side the application of appropriate technologies and infrastructure. This elements are essential for the logistics enterprises to develop innovate and efficient logistics services realized in appropriate organized environment.

On the field of warehousing, the potential to achieve goals of sustainable development is not fully researched and the problem is often considered in terms of assessing the level of sustainable development using the existing building certification standards (BREEAM (Building Research Establishment Environmental Assessment Methodology), LEED (Leadership in Energy and Environmental Design), DGNB (Deutsche Gesellschaft für Nachhaltiges Bauen) [Hamedani and Huber 2012, Mokrzecka 2015]. However, this approach doesn't fully cover the concept of sustainable warehousing, which goes beyond the building facilities [Amjed and Harrison, 2013]

In the article it is presented an approach to elaborate the sustainable warehousing assessment model, which will focus on different dimensions of sustainability, and in particular those optimizing the building design, referring to the applied technological solutions and increasing the efficiency and comfort of work. To elaborate the model one of the existing multicriteria decision-making method (MCDM) named as COMET method (characteristic object method) was implemented. Such approach allowed to propose a dedicated model, which can be from one side an important step towards finding the sustainable warehousing assessment tool, and from the other can indicate to the warehouses' owners, which area requires to be improved to achieve the better grade in the future. 


\section{SUSTAINABLE DEVELOPMENT AS A ROADMAP FOR MODERN WAREHOUSING}

The concept of sustainability has firmly set itself in the strategies of companies in different branches. New requirements and emerging restrictions of running the company involved with growing customer demands, rising cost of work, higher social expectations, growing global competition and more restricted environmental regulations cause the necessity to apply more effective methods of management. This methods should let keep balance between three spheres of sustainable development, namely the economic, social and environmental ones.

The realization of this goal, in accordance with the fundamental definition of sustainable development, in general is focusing to meet the needs of the present without compromising the ability of future generations to meet their own needs [International Institute for Sustainable Development, 2019]. To reach the economic sustainability in highly competitive environmental global, the economic issues should not only concerned with costs or profits, but also result from quality, efficiency or reliability [Wichaisri and Sopadang 2013]. As indicate [Circular Ecology 2019], the economic sustainability requires to utilized the possessed resources in efficient and responsible way to consistently produce an operational profit consisting the fundamental issue to maintain the activities realized by the company in long term perspective.

Economic challenges are not isolated from environmental and social ones. Negative impact on the natural environment caused by ozone depletion, accumulation of $\mathrm{CO} 2$ and other greenhouse gases, waste generating, raising energy usage, high level of fossil fuel consumption as well as raising water consumption requires to provide broader discussion and new spectrum of actions focusing on ensuring higher standards of resource utilization, life, health and safety [El-Berishy et al. 2013, Adams 2006]. From the social point of view it is necessary, from one side, to rise up people's awareness towards this problems, and from the other to achieve a good social well being both intra-organizational stakeholders (employees in an organization) and inter-organizational stakeholders (suppliers, customers and communities).

Traditionally, companies emphasize costs and profits when analyzing their business operation, but application of the sustainable development approach requires the integration between economic, environmental and social actions. This goal is also guiding the sustainable logistic systems, in which sustainable development as well as greening aspects appear as key issues facing logistics activities [El-Berishy et al. 2013]. A sustainable logistics system focuses on logistics operations (i.e., supplier selection, procurement, manufacturing, warehousing, 
and delivery) in order to reduce a company's costs, lessen its environmental impact, and address the impact it has on society. Sustainable logistics offer companies economic, environmental, and social benefits, such as an increase in asset utilization, enhanced customer service, increased energy efficiency, reduced impact on the community, and improved quality of life [Wichaisri and Sopadang 2013]. Logistics enterprises are oriented to develop innovative and efficient logistic services, which will follow the three dimensions of sustainable approach. As mention El-Berishy, Rügge and Scholz-Reiter [El-Berishy et al. 2013] sustainability might be considered as one of the measures that can judge the situation of any enterprise internationally.

To measure the level of sustainable development it is necessary to propose a tool enabling such assessment, which will takes into considerations broad aspects of sustainability and allows to compare the results achieved by different units. The crucial is to apply aspects suitable for the considered problem.

When the aim of the research is warehouse and its functioning there can be distinguished several indicators including the applied warehouse solutions and management processes organization guidelines, energy efficiency within a warehouse, optimization of warehouse design, application of social policy to ensure higher standards of work and awareness of the employees towards sustainability. Such approach is reflected in the definition presented by Żuchowski [Żuchowski, 2015], who considered the sustainable warehouse and interpret it as a set of organizational and technological solutions whose aim is to efficiently execute warehouse processes, with the highest social standards met, with the lowest possible environmental impact and taking financial effectiveness into account.

The analysis of this definition lets to notice, that the made assumptions go beyond the warehouse as a building and touch also the warehouse operations. This highlights that not only building design but also the running of warehouse holds potential for achieving goals of sustainable development. The above remarks are coincidented with the research presented by Amjed and Harrison [Amjed and Harrison, 2013], who focused on elaboration the theoretical sustainable warehousing model as a response for less attention dedicated for warehousing despite its tremendous potential to achieve the goals of sustainable development. As show the statistics, warehousing is perceiving as one of the most critical functions in a supply chain which constitutes 24 percent of logistical costs, so the idea to look for its optimization towards sustainable development seems to be appropriate [Harrison and Amjed, 2013]. 


\section{IDENTIFICATION OF THE CRITERIA OF SUSTAINABLE WAREHAUSING}

To identify the criteria affected the warehouse sustainability, there should be provided the analysis concerning such issues as warehouse design and construction, warehouse staff, warehouse processes, warehouse management system, onsite facilities and handling equipment. The scope of selected criteria can be partially determined on the basis of building certification standards (i.eg. BREEAM, LEED), which indicate crucial aspects referring to location, design, construction, maintenance and demolition of the building. In the literature, the practical aspects of sustainability issues referring to warehouse functioning and the modeling approaches to achieve higher social standards, better financial effectiveness and more environmental friendly environment were presented in the work [Xu 2016, Boenzi 2015, Amjed and Harrison 2013, Tan et al. 2010]. Amjed and Harrison [Amjed and Harrison 2013] described eight sustainable warehousing constructs within which there are included elements presenting various dimensions of sustainability.

On the basis of the literature review 22 criteria were distinguished (Fig. 1). The criteria refer to both the technologies and materials used for designing and building the warehouse as well as applied equipment (advancements and application), procedures and standards to promote environmental friendly behaviors and achieve better organization of processes and work conditions [Malinowska et.al 2018].

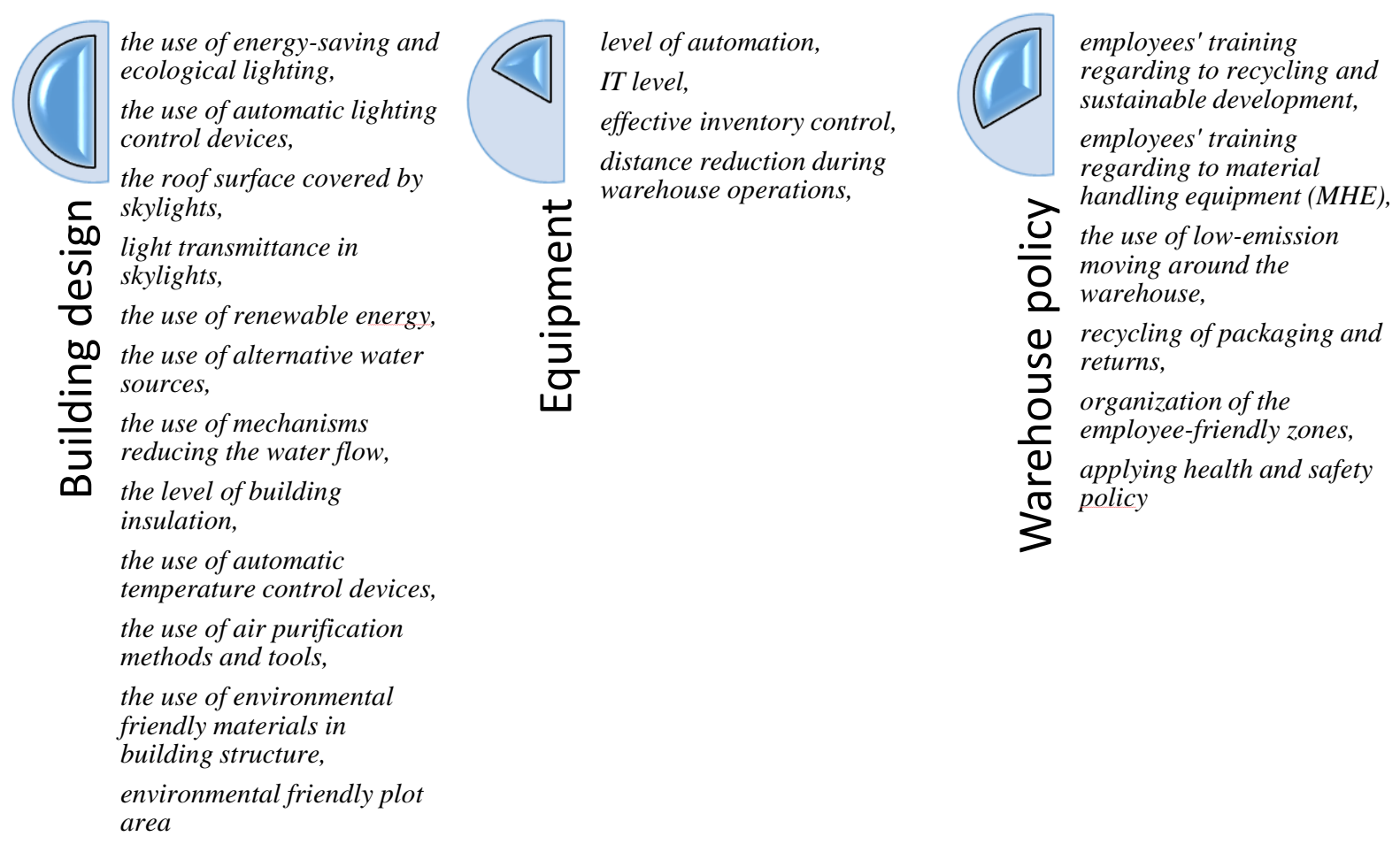

Fig. 1. The range of criteria indicated for the purpose of sustainable warehousing assessment model elaboration

A. Kolinski et al. (eds.), Contemporary challenges in supply chains, Vol. 1, https://doi.org/10.17270/B.M.978-83-66017-88-7.9 
Source: own work based on [Malinowska et.al 2018].

Determining the set of criteria lets to established the space of the considered problem. For the purpose of model creation, however, it is required that for each criteria will be assign the scale of its measurement. In [Malinowska 2019], there were presented some proposal for such criteria as level of the building isolation, employees' training regarding to recycling and sustainable development. Identification the whole range of criteria in the same way is necessary to start working under the model dedicated to inference about warehouse sustainability.

\section{SUSTAINABLE WAREHAUSING ASSESSMENT MODEL - APPROACH AND GENERAL CONSTRUCT}

Elaboration of the sustainable warehousing assessment model is a complex task, which main objective can be captured in three main fields:

- To identify factors that matter for sustainable warehousing;

- To define and provide a methodological approach for sustainable warehousing assessment model elaboration;

- To provide a model enabling the assessment of the level of sustainable warehousing, on the basis of which the achieved inferencing results might be the background for discussion and actions initiated in warehouse to select the strategy of improvement the result as a whole or in a chosen parts.

The identification of 22 criteria with the specified measure for each of them is a difficult task. It requires, from one side, the expert knowledge from different domains to propose a complex set of criteria and a scale of their measurement. From the other side, it is crucial for the purpose of establishing the way of achieving the final grade of the level of sustainable warehousing.

Regarding the fact that considered problem refers to making the multi-criteria decisions, the COMET method (the Characteristic Objects Method) was chosen for its implementation. COMET represents the multi-criteria decision-making method (MCDM), but unlike the other well known methods i.eg. AHP, TOPSIS, allows to eliminate the phenomenon of rank reversal [Wątróbski and Sałabun 2016].

Using the COMET method, one should follow the order of given procedures steps. It starts with defining a specific problem space, then characteristic objects are generated as well as their ranking and evaluation is proceed (by determining the matrix of expert assessments). In the 
fourth step, a rules base is created as a result of directly reformed the collected characteristic objects. The last stage of procedure, however, involves conducting fuzzy inference and receiving the final ranking [Sałabun 2014].

The given procedure causes, that COMET method assesses alternatives using a model identified on the basis of characteristic objects that are independent from the set of assessed decision variants. This means that, unlike many other methods of multi-criteria decisionmaking analysis, there is no comparison of the assessed decision variants between each other, and the result of assessment is only inferred from the obtained model. The decision model defines the assessment pattern for all decision variants of a given problem [Sałabun et al. 2019, Sałabun 2014].

The model assessing the level of sustainable warehousing was elaborated on the basis of the selected set of criteria presented in previous section (Fig. 2). Proceeding the whole procedure of COMET method and applying the approach to reduce the dimensionality of the model allowed to express, in final aggregation, the level of sustainability in terms of natural language using the 5-elements scale: very low level of sustainability, low level of sustainability, medium level of sustainability, high level of sustainability, very high level of sustainability.

For each criterion of the model there was identified the scale of measurement as well as established the characteristic values (Fig. 3). The preparation of criterion describing the employees' training regarding to material handling equipment was based taking into account the percentage of employees participated in appropriate training. In this case the scale is defined in a domain $0-100 \%$. Additionally is was proposed a set of characteristic values expressed in natural language with the values $\{$ low, medium, high $\}$. Identification of characteristic values for a given criterion was made using the trapezoidal fuzzy number [Kabir and Papadopoulos 2018].

The process of sustainable warehousing assessment model creation was proceed applying the reduction of dimensionality of possible alternatives by creating the mini-models (local models): from A1 to A19. The application of a hierarchical structure caused that the final model is assembled from the connected local models and the outputs from the previous models are input for the next ones. The crucial effort is to determine the correct structure, which is not always easy to obtain. The general rule of hierarchy designation indicates that criteria that are related to each other should be grouped together provided the new variable, which is easily understood by the expert. 


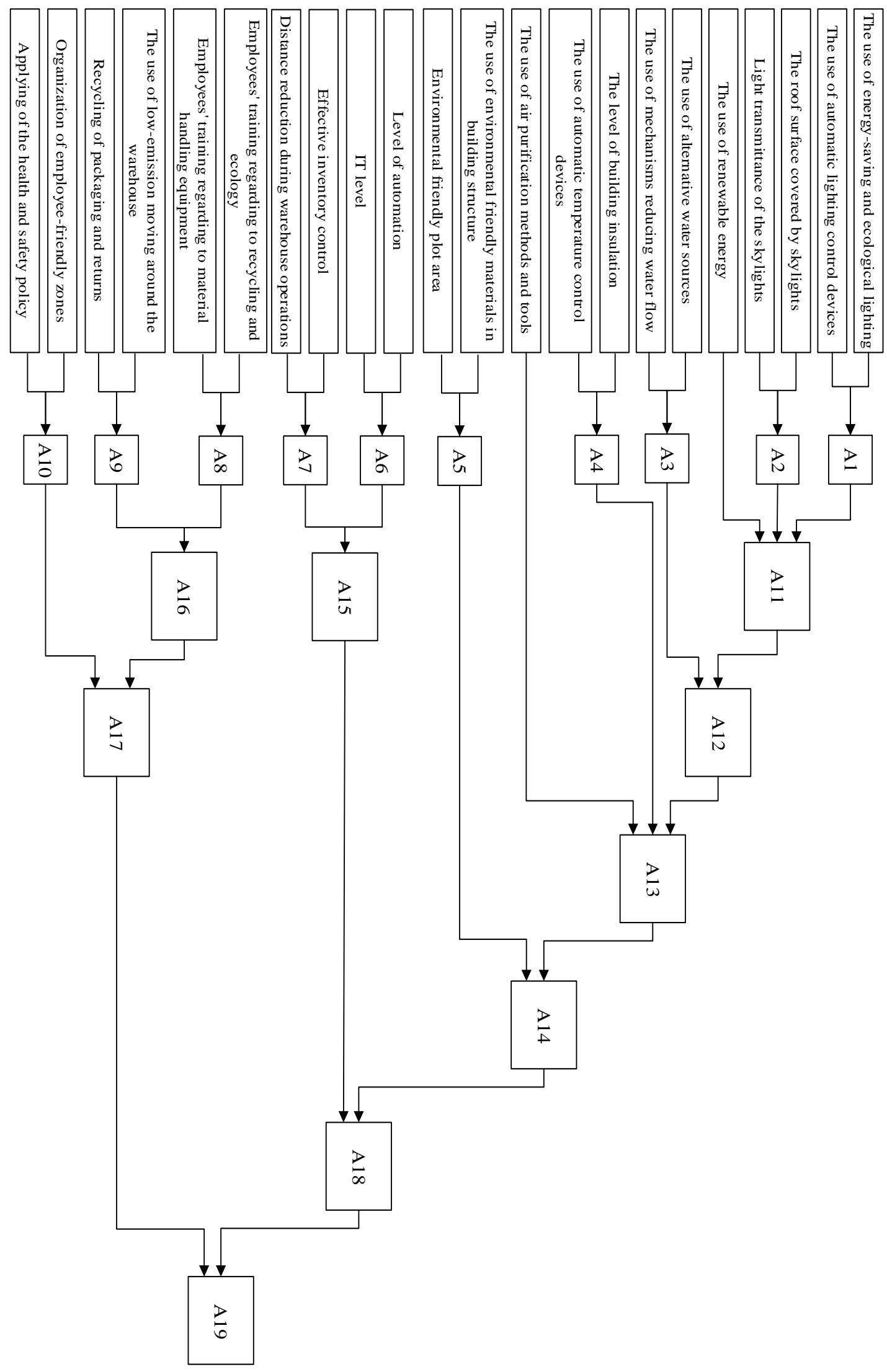

A. Kolinski et al. (eds.), Contemporary challenges in supply chains, Vol. 1, https://doi.org/10.17270/B.M.978-83-66017-88-7.9 
Fig. 2. The concept of the warehouse sustainability assessment model Source: [Malinowska et al. 2018]

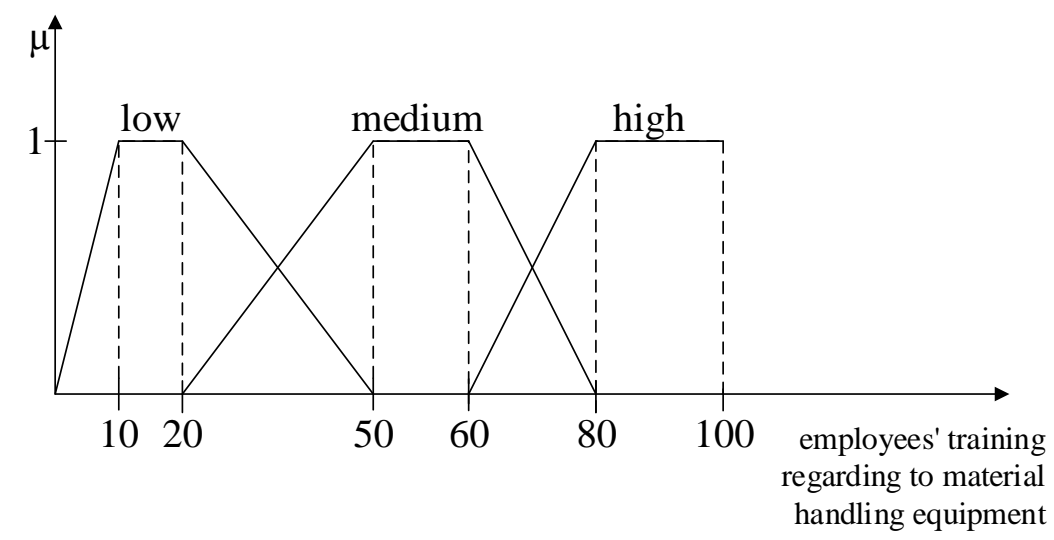

Fig. 3. The characteristic of criterion describing the employees' training regarding to material handling equipment (source: own elaboration).

Source: own work.

Inferencing on the basis of prepared model lets to answer the following questions:

- What is the level of sustainable warehousing in the assessed unit,

- What are the differences in sustainability of warehouses among different organizations taking part in the assessment?,

- Which factors get the highest score considering the results achieving while assessment of different units?.

The prepared model might be a good opportunity to create a system dedicated to manage the warehouse development in accordance with the sustainability approach. The identification of the weakest areas with low grade during the evaluation can be the clue for warehouses' owners determining what should be improved to get the higher score in the future. Additionally, the system might be utilized to compare warehouses with each others.

\section{CONCLUSIVE REMARKS}

The sustainable development research provided on different fields of logistics require to put attention also on the aspects referring to the warehouse functioning to propose such a unit which will ensure higher standards of work from the environmental, social and economic point of view. However to achieve this it is necessary to indicate the level of sustainability of the analyzed area of the research.

This article presents the general approach to apply the COMET method for the purpose of sustainable warehousing assessment model elaboration. The model was created on the basis of 
the literature review and expert judgement. However, there are still conducting analysis referring to its complexity as well as the propriety of the used scales. Since the model was based on the expert knowledge and experience, it seems reasonable to provide the verification of given assumptions by wider body.

\section{REFERENCES}

Adams W.M., 2006, The Future of Sustainability: Re-thinking Environment and Development in the Twenty-first Century. Report of the IUCN Renowned Thinkers Meeting. Available on the Internet: http://cmsdata.iucn.org/downloads/iucn_future_of_sustanability.pdf.

Amjed T. W., Harrison N. J., 2013, A Model for sustainable warehousing: from theory to best practices, A. E. Avery (Ed.), 2013 International DSI and Asia Pacific DSI Conference proceedings, United States: Decision Sciences Institute, 1892-1919.

Boenzi F., Digiesi S., Facchini F., Mossa G., Mummolo G., 2015, Sustainable Warehouse Logistics: a NIP Model for non-road vehicles and storage configuration selection, XX Summer School "Francesco Turco - Operational, Excellence, Experiences", 263-270, Available on the Internet:http://summerschool-aidi.it/edition2015/images/Naples2015/proceed/29_facchini.pdf.

Circular Ecology, 2019, Sustainability and sustainable development - What is sustainability and what is sustainable development? Available on the Internet: http://www.circularecology.com/sustainability-and-sustainabledevelopment.html\#.XazcT2gza73.

El-Berishy N., Rügge I., Scholz-Reiter B., 2013, The Interrelation between Sustainability and Green Logistics, 6th IFAC Conference on Management and Control of Production and Logistics, 46 (24), 527-531, DOI: 10.3182/20130911-3-BR-3021.00067.

Hamedani A. Z., Huber F.A., 2012, Comparative study of DGNB, LEED and BREEAM certificate systems in urban sustainability, The Sustainable City VII, 1, 121-132, DOI: 10.2495/SC120111.

Harrison N.J., Amjed T.W., Sustainability determinants for food supply chain: Developing a qualitative methodology, 8th International Symposium on Sustainable Leadership, Available on the Internet: https://instituteforsustainableleadership.com/wpcontent/uploads/2014/08/ISL-conf-proceedings-2013.pdf\#page=49.

International Institute for Sustainable Development, 2019, Sustainable Development, Available on the Internet: https://www.iisd.org/topic/sustainable-development. 
Kabir S., Papadopoulos Y., 2018, A review of applications of fuzzy sets to safety and reliability Engineering, International Journal of Approximate Reasoning, 100, 29-55, DOI: https://doi.org/10.1016/j.ijar.2018.05.005.

Malinowska M., Rzeczycki A., Sowa M., 2018, Roadmap to sustainable warehouse InfoGlob 2018 SHS Web of Conferences 57, $01028 \quad$ (2018), 1-9, DOI: $10.1051 /$ shsconf/20185701028.

Malinowska M., 2019, An approach to develop the sustainable warehousing assessment model, ICTLE 2019, MATEC Web of Conferences, Volume 296, 02005 (2019), 1-5, DOI: https://doi.org/10.1051/matecconf/201929602005.

Mokrzecka M., 2015, Międzynarodowe systemy certyfikacji LEED, BREEAM I DGNB Wstępna analiza porównawcza poparta studium przypadku, Journal of Civil Engineering, Environment and Architecture, XXXII 62 (2/15), 311-322, DOI: 10.7862/rb.2015.60.

Sałabun W., Piegat A., Wątróbski J., Karczmarczyk A., Jankowski J., 2019, The COMET method: the first MCDA method completely resistant to rank reversal paradox, European Working Group "Multiple Criteria Decision Aiding". Available on the Internet: ttps://www.researchgate.net/publication/333843850.

Sałabun W., 2014, The Characteristic Objects Method: A New Distance- based Approach to Multicriteria Decision- making Problems, Journal of Multi- Criteria Decision Analysis, 22 (1-2) 37-50, DOI: https://doi.org/10.1002/mcda.1525.

Tan K, Daud A.M., Sundaram D., 2010, Sustainable enterprise modelling and simulation in a warehousing context, Business Process Management Journal, 16 (5), 871-886, DOI: $10.1108 / 14637151011076511$

Wątróbski J., Sałabun W., 2016, The Characteristic Objects Method: A New Intelligent Decision Support Tool for Sustainable Manufacturing, Sustainable Design and Manufacturing 2016, Switzerland: Springer Int. Pub., 349-359, DOI: 10.1007/978-3-31932098-4_30.

Wichaisri S., Sopadang A., 2013, Sustainable logistics system: A framework and case study, 2013 IEEE International Conference on Industrial Engineering and Engineering Management, DOI: 10.1109/IEEM.2013.6962564.

Xu Ch., Xiaojun W., Vikas K., Niraj K., 2016, Low carbon warehouse management under capand-trade policy, Journal of Cleaner Production, 139, 894 - 904, DOI: 10.1016/j.jclepro.2016.08.089. 
Żuchowski W., 2015, Division of environmentally sustainable solutions inwarehouse management and example methods of their evaluation, LogForum, 11 (2), 171-182, DOI: 10.17270/J.LOG.2015.2.5.

A. Kolinski et al. (eds.), Contemporary challenges in supply chains, Vol. 1, https://doi.org/10.17270/B.M.978-83-66017-88-7.9 